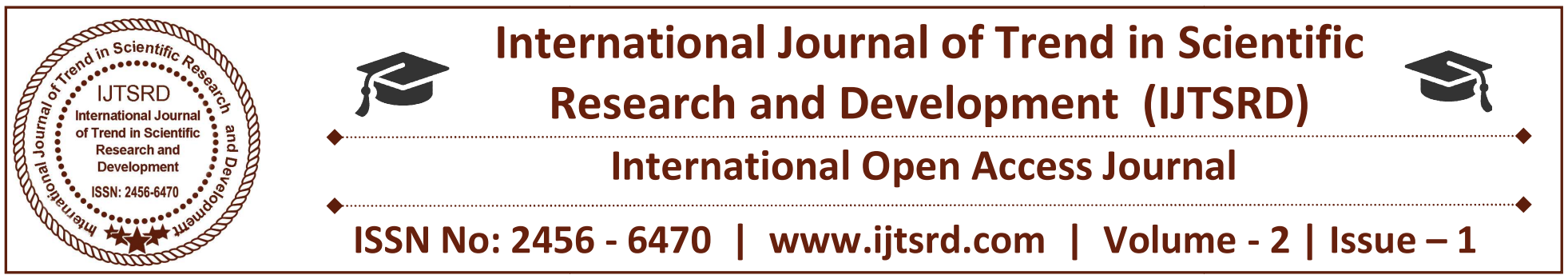

\title{
Modeling a Multivariable Process Control System using PID Optimization
}

\author{
Aguodoh Patrick C . \\ Michael Okpara. University of Agriculture \\ Umudike, Abia State, Nigeria
}

\author{
Chiagunye Tochukwu T. \\ Michael Okpara. University of Agriculture \\ Umudike, Abia State, Nigeria
}

\section{ABSTRACT}

Many process control model have been observed to have unsatisfactory output variables, such as pressure, composition, temperature, at specified values, giving rise to overshoot and unbounded responses. A lot of methods have been adopted to curb this undesirable effect, starting from the use of different configurations of controllers. This paper presents the model of a multivariable process control using labview proportional, integral and derivation controllers (PID). Modeling and control of multivariable process using optimization can be effectively achieved by optimization of proportional, integral, derivative volume of liquid $\mathrm{L}$ coupled with using appropriate transfer functions and accurate labview controllers for the modeling to achieve the controlling of the volume of cold and hot water to be in the proportion of 3:1.

Keywords: Labview, PID Controller, Multivariable, Overshoot, simplex optimization

\section{INTRODUCTION}

Modeling and control of multivariable process using optimization is the control of level and temperature of liquid in tanks and flow between tanks are the basic problem in the process industries. To achieve this level control of liquid, optimization using PID method is used in this project. The process control industries require liquids which are to be pumped as well as stored in tanks and then pumped to another tank. Most of the times, the liquids will be processed in the tanks, but always the level and temperature of liquid in the tanks have to be controlled and the flow between tanks have to be regulated. As the tanks are so coupled together that the levels in tanks interact with each other and this must also be controlled. Systems which have more than one input and or more than one output are called multiple input multiple output (MIMO) system (Wayne Bequette, 2003)

Tank level control system are used frequently in different processes. All of the process industries, the human body and fluid handling system depend upon tanks level control systems. The control system engineers have to understand how thermal control systems work and how the level control problem is achieved. However, interactions existing between loops make it more difficult to design PI and PID controllers (Wang, 2009) for MIMO processes than for single input single output (SISO) ones and have attracted attention of many researcher in recent years.

Thermal control systems are also used frequently in different processes. The thermal control system is non linear time varying and consists of multivariable. Hence, the control of such system is complex and challenging. It is a challenging task for control system engineers to understand how thermal control systems work and how the control of temperature of liquid in the tank is achieved. The description of a system using mathematical concepts and language is called a mathematical model. A mathematical model helps to explain a system and to study the effects of different components, and to make predictions about their behavior. Mathematical models can take many forms like dynamical systems, statistical models or differential equations. Hence, mathematical model of the components of the thermal control system is very important for design and analysis of the control system.

The output of the MIMO process can either be interacting or non-interacting. If one output is affected 
by only one input, then it is called interacting system. In MIMO system, the input variable which causes interaction between the input variable affects the output which causes interaction between the input and output loops. So, the control of multivariable systems is much more difficult compared to the SISO system. Therefore, the degree of interaction plays an important role to quantify the proper input and output pairings that minimize the impact of the interaction. The interaction between inputs and outputs can be eliminated by using decouples, cross controllers or many other methods.

\section{Problem Statement}

The control of liquid levels and its temperature has become a problem. Such problems include how to:

i. To determine the maximum level of liquid for the manufacturing processing using simplex optimization method

ii. Monitor and control of water levels

iii. Monitor and control of temperature limits in thermal processes

iv. To analysis the manufacturing electric signals

v. Deal with Vibration analysis

\section{Research Objective}

The research objective of this project titled modeling and control of multivariable process using labview are as follows:

i. To determine maximum liquid level a tank could hold for processing using optimization.

ii. To determine the control level of the liquid by using proportional, integral and derivative PID.

iii. To determine and monitor the liquid level and temperature limits in thermal processing using laboratory virtual instrumentation engineering work bench.

\section{Significant of the Study}

i. Modelling and controlling of multivariable process using laboratory virtual instrumentation helps liquid manufacturing industries like brewery industry to maintain a standard level.

ii. It helps the liquid manufacturing to produce quality goods. iii. It increases the economic growth of the industries that uses modeling and control of multivariable process using labview.

\section{METHODOLOGY}

Modeling and control of multivariable process such as liquids using laboratory virtual instrumentation engineering work bench (labview) is the primary objective of this research.

To achieve this perfectly well, optimization method is used to optimize the proportional integral derivative of the transfer functions.

These are the procedures used to achieve this

i. Using optimization to find the values of proportional "P" and integral "I", derivative "D" and the desired liquid level.

ii. Using the following transfer functions for the modeling

$$
\mathrm{G} 11_{(\mathrm{s})}=\frac{0.25 \mathrm{~s}+0.75}{0.25 \mathrm{~s}^{2}+1.125 \mathrm{~s}+1}
$$

Transfer function for cold water level

$$
\begin{aligned}
\mathrm{G} 12_{(\mathrm{s})} & =\frac{0.25}{0.255 \mathrm{~s}^{2}+1.125 \mathrm{~s}+1} \\
\mathrm{G} 21_{(\mathrm{s})} & =\frac{0.25}{0.25 \mathrm{~s}^{2}+1.25 \mathrm{~s}+1}
\end{aligned}
$$

Transfer function for hot water level.

$$
\mathrm{G} 22=\frac{0.5 \mathrm{~s}+0.75}{0.25 \mathrm{~s}^{2}+1.125 \mathrm{~s}+1}
$$

Transfer function for temperature of hot and cold

iii. Using labview controller to control the desired liquid level for hot and cold water.

$$
\begin{aligned}
& \text { Maximize L }=60 \mathrm{p}+45 \mathrm{I}+25 \mathrm{D}-\quad-\quad-\quad-\quad-\quad \text { - } \quad .1
\end{aligned}
$$

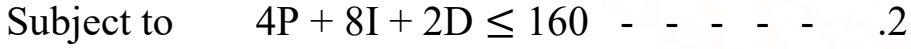

$$
\begin{aligned}
& 6 \mathrm{P}+3 \mathrm{I}+4 \mathrm{D} \leq 168-\quad-\quad-\quad 3 \\
& 4 \mathrm{P}+3 \mathrm{I}+3 \mathrm{D} \geq 128 \ldots \ldots
\end{aligned}
$$

Then, adequate equation 1 to zero, and remove the constraints in equations 2 and 3 by introducing slacks and change the constraint of greater than and equal to in equation 4 to less than and equal to by multiplying 
it by minus one. Finally remove the constraint in equation 4 by introducing.

$$
\begin{aligned}
& \mathrm{L}-60 \mathrm{p}-45 \mathrm{I}-25 \mathrm{D}+\mathrm{MS}_{4}=0 \\
& 4 \mathrm{p}+8 \mathrm{I}+2 \mathrm{D}+\mathrm{S}_{1}=160 \\
& 6 \mathrm{p}+3 \mathrm{I}+4 \mathrm{D}+\mathrm{S}_{2}=168 \\
& 4 \mathrm{p}+3 \mathrm{I}+3 \mathrm{D}-\mathrm{S}_{3}+\mathrm{S}_{4}=128
\end{aligned}
$$

\section{Step A}

Fill in the coefficients of equations 5,6 and 7 in the table1 for iteration.

\section{Step B}

The key column falls at the most negative at $\mathrm{L}$ row of iteration I which is -60 , so it falls at $\mathrm{P}$ column.

$-7$

$-8$

To find the key row use the positive numbers in the key column to divide their respective solutions,

Step C

Table 1: iteration 1

No of iterations

$\mathrm{S}_{2}$

Leaves

\begin{tabular}{|c|c|c|c|c|c|c|c|c|c|c|}
\hline $\mathbf{S}_{2}$ & $\mathrm{~L}$ & 1 & 0 & -15 & 15 & 0 & 10 & 0 & M & 1680 \\
\hline Leaves & $\mathrm{S}_{1}$ & 0 & 0 & क & $-2 / 3$ & 1 & $-2 / 3$ & 0 & 0 & 48 \\
\hline I & $\overline{\mathrm{P}}$ & $\overline{00}$ & 1 & 茠 & $2 / 3$ & $\bar{~} 0$ & $1 / 6$ & 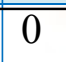 & 0 & 28 \\
\hline Enters & $\mathrm{S}_{4}$ & 0 & 0 & 1 & $1 / 3$ & 0 & $-2 / 3$ & -1 & 1 & 16 \\
\hline \multicolumn{11}{|c|}{ Table 3: iteration 3} \\
\hline $\mathrm{S}_{4}$ & $\mathbf{L}$ & 1 & 0 & 0 & $40 / 3$ & $5 / 2$ & $25 / 3$ & 0 & $\mathbf{M}$ & 1800 \\
\hline Leaves & $\mathrm{S}_{4}$ & 0 & 0 & 1 & $-1 / 9$ & $1 / 6$ & $-1 / 9$ & 0 & 0 & 8 \\
\hline I & $\mathrm{P}$ & 0 & 1 & 0 & $13 / 18$ & $-1 / 12$ & $2 / 9$ & 0 & 0 & 24 \\
\hline Enters & $\mathrm{S}_{4}$ & 0 & 0 & 0 & $10 / 9$ & $-1 / 6$ & $-5 / 9$ & -1 & 1 & 8 \\
\hline
\end{tabular}

$\mathrm{P}$

Enters

Table 2: iteration 2

$\begin{array}{lll}\mathrm{L} & = & 1800 \text { LITRES } \\ \mathrm{I} & = & 8 \\ \mathrm{P} & = & 24 \\ \mathrm{D} & = & 0\end{array}$

\section{System Simulation and Data Analysis}

The model and control of multivariable process using optimization is designed in figs 1 and 2 which are meant for 1800 liters to generate 1350 liters for cold water and 450liters for hot water respectively when simulated .

The maximum liters of liquid which is 1800 got from the optimization is used to pour in the system for it to be processed into hot and cold water. 
The design was done in such a way that the proportional of the cold water to the hot water when processed is $3: 1$.

Although maximum liters of liquids were varied as follows 2500, 3000, 3500, 4000, 4500 and 5000 liters which were also poured in the system for it to be processed into cold and hot water. When the process rounded up, the proportion of the cold water to the hot water obeyed the specification of the design which is 3: 1 ratio.

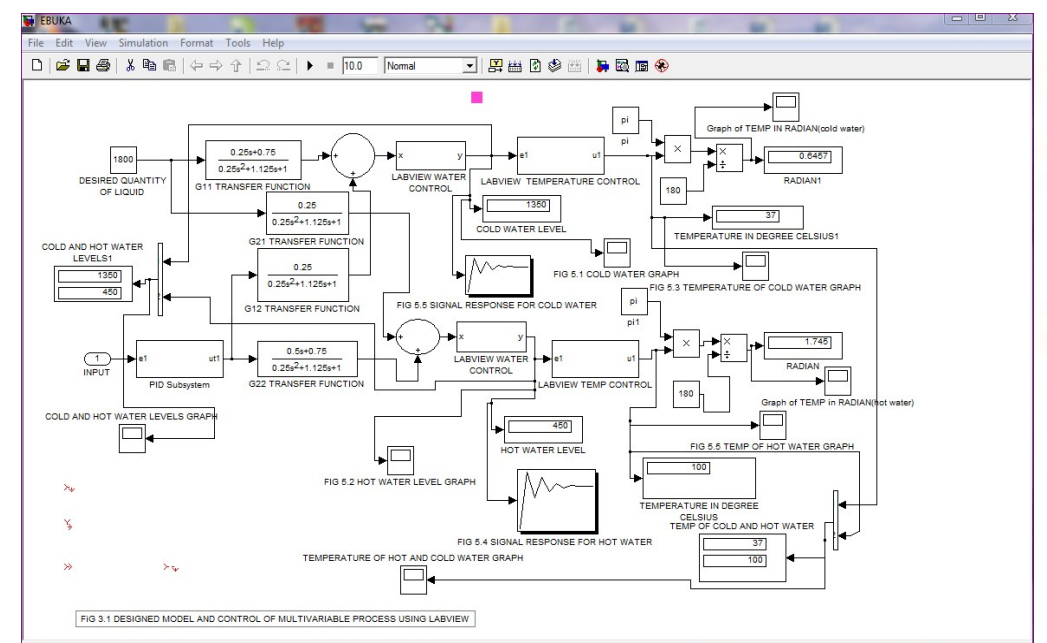

\section{FIG 1 DESIGNED MODEL AND CONTROL OF MULTIVARIABLE PROCESS USING OPTIMIZATION AT A VOLUME OF 1800 LITERS}

Fig 1 shows that when 1800 liters of water is simulated with appropriate transfer function the volume of cold water is 1345 liters while that of hot water is 450 liters respectively.

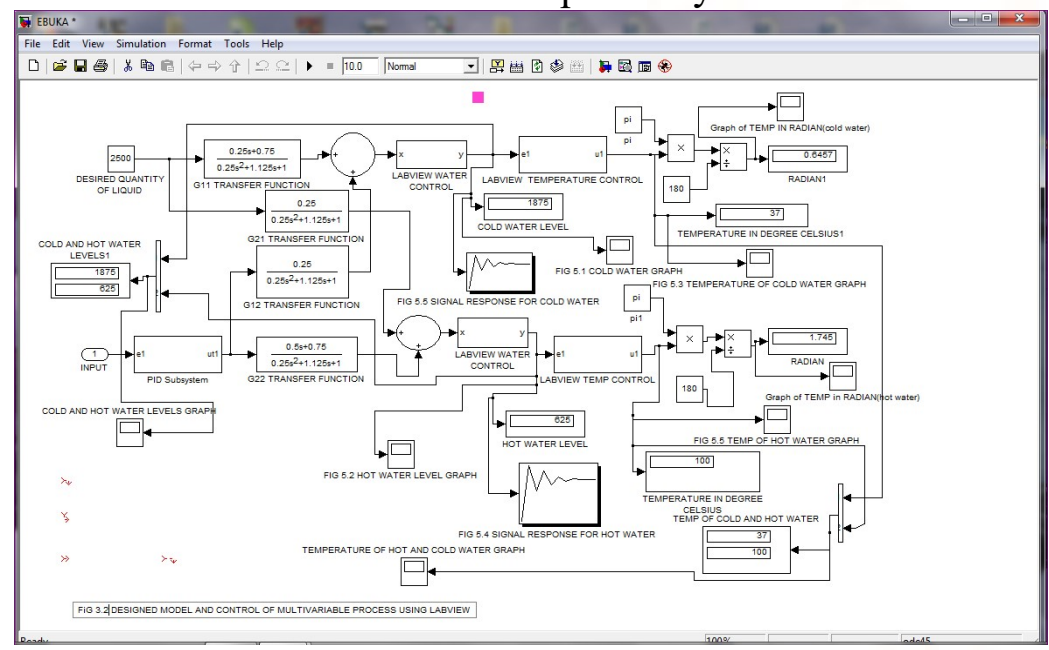

\section{FIG 2: DESIGNED MODEL AND CONTROL OF MULTIVARIABLE PROCESS USING OPTIMIZATION AT A VOLUME OF 2500 LITERS}

Fig 2 shows that when 2500 liters of water is simulated with appropriate transfer function the volume of cold water is 1875 liters while that of hot water is 625 liters respectively.

The results gotten in figs 1 and 2 show that the proportion of cold to hot water is $3: 1$

\section{Result Analysis}

Firstly, when 1800 liters of water is simulated the volumes at different times are shown in tables 1 and 2 for cold water level of 1350 liters and hot water level of 450 liters. 


\begin{tabular}{|c|c|} 
Table1 Cold Water Level 1350 Liters \\
\hline Time(s) & Volume (liters) \\
\hline 10 & 1350 \\
\hline 9 & 1350 \\
\hline 8 & 1350 \\
\hline 7 & 1350 \\
\hline 6 & 1350 \\
\hline 5 & 1350 \\
\hline 4 & 1350 \\
\hline 3 & 1350 \\
\hline 2 & 1200 \\
\hline 1 & 1000 \\
\hline 0 & 0 \\
\hline
\end{tabular}

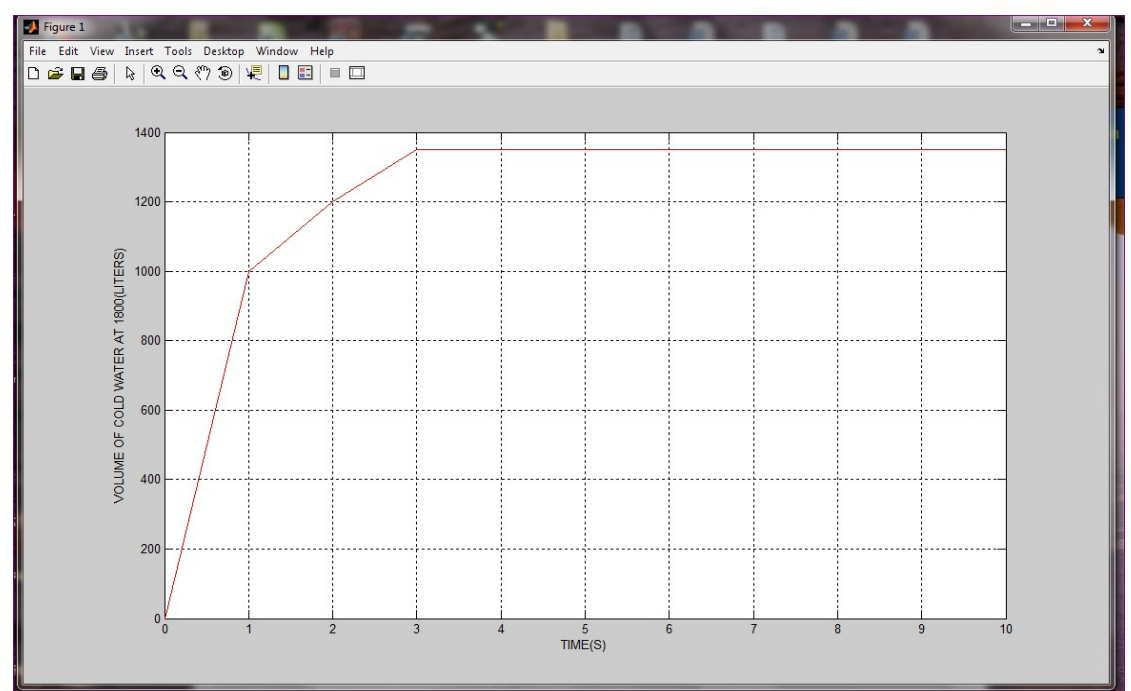

FIG 3 COLD WATER LEVEL AT 1350 LITERS

Fig. 3 shows the graph of cold water level when 1800 liter of water is poured in the system for it to be processed. It is seen from the graph that from $0 \mathrm{sec}$ through 2 seconds the graph is linear and from 3 seconds through 10 seconds the volume of cold water in the thank is controlled to a constant level of 1350

Table2 Hot water Level 450 Liters

\begin{tabular}{|c|c|}
\hline Time(s) & Volume (liters) \\
\hline 10 & 450 \\
\hline 9 & 450 \\
\hline 8 & 450 \\
\hline 7 & 450 \\
\hline 6 & 450 \\
\hline 5 & 450 \\
\hline 4 & 450 \\
\hline 3 & 450 \\
\hline 2 & 250 \\
\hline 1 & 1000 \\
\hline 0 & 0 \\
\hline
\end{tabular}




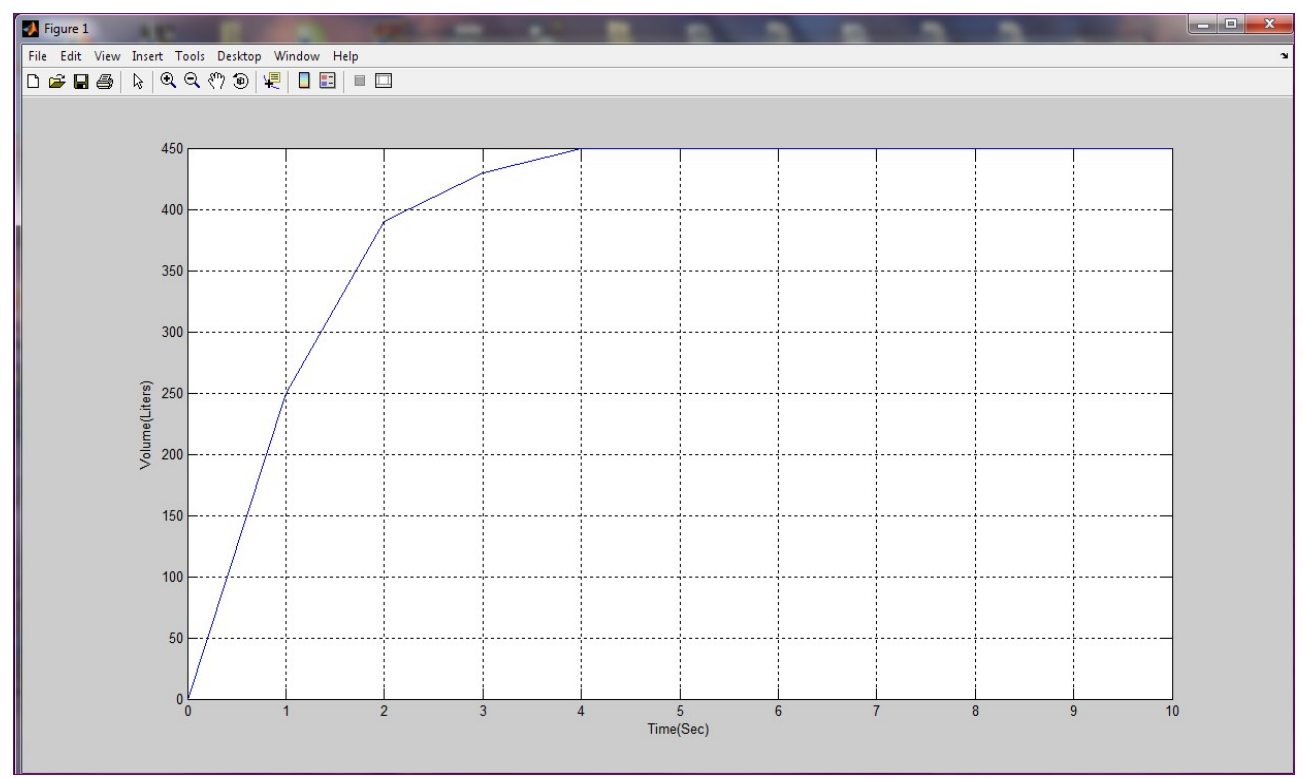

FIG 4 HOT WATER LEVEL AT 450 LITERS

It is equally seen from fig 4 that from 0 second through 3 seconds the level of water in the tank increases linearly while from 4 seconds through 10 seconds the water in the tank maintained a constant volume of 450 liters.

From the result gotten it is seen that the proportion of cold water to hot water is $3: 1$

\section{Conclusion}

Modeling and control of multivariable process using optimization can be effectively achieved by optimization of proportional, integral, derivative volume of liquid L coupled with using appropriate transfer functions and accurate labview controllers for the modeling to achieve the controlling of the volume of cold and hot water to be in the proportion of $3: 1$.

\section{REFERENCES}

\section{Atashpaz E. Hashemzadeh and LUCas,} Designing MIMO PID controller using colonial competitive algorithm: Applied to Distillation Column process" IEEE congress on Evolutionary computation (CEC 2008). Hong Kong China, PP $1929-1934,2008$

2. Bart Q.J "Synthesis of a Decentralized fuzzy controller for level control of four stage cascade Tank system, " African Conference, $6{ }^{\text {th }}$ IEEE AFRICON, Vol 1, PP 119 - 122, 2003

3. Besson $\mathbf{V}$ and Shenton "Interactive control system Design by a mixed $\mathrm{H} 2$ parameter space method IEEE Trans, Aut. Contr. Vol 42, No 7, PP $946-955,1997$.
4. Bristol E, "On a new measure of interaction for multivariable process control, "IEEE Transaction on Automatic control, vol 11, no 1, pp 133 - 134

5. Chen H.M, Chen Z.Y. "Design of a shiding mode controller for a liquid tank level control system", IEEE proceeding of international conference on innovative computing, information and control, S, Kumamoto, Japan , 2007

6. Camacho, and Rojas R, "A General Sliding mode controller for nonlinear" chemical process transaction of the ASME, Vol 22, December 2000

7. Cohen G.H. and Coon G.A, "Theorical consideration of Retarded control", Trans ASME, Vol 75 PP 827 - 834, 1953

$\begin{array}{lllll}\text { 8. Cornieles } \mathbf{E} \text { and Bougeret } & \text { C. “ } \\ \text { Comparaisonexperimentalededifferentes } & & \end{array}$ techniques de reglagae du regulateur PID et Dual loop”, Rapport official R97,EPM, 1997

9. Cornieles S. E, Saad M, Gauthiev G. and Saliah - Hassane H. "modeling and simulation of multivariable process control. " proceedings of IEEE international symposium on industrial Electronic Vol 4, pp 2700 - 2705, 2006

10. De Sautis R.M, "A novel PID configuration for a speed and position control" Transaction of the ASME, Vol 116, pp. 542 - 549, September 1994

11. Fan Y, and Xia M.T“ Gradient control of liquid level control system dynamics", proceeding of the $3^{\text {rd }}$ world congress on international control and Automations PP 3294 - 3297, June 28 - July 2, China 2000 
12. Garcia C.E and Morari, "Design procedure for multivariable interaction control systems Automatica, vol 7 pp 691 - 701, 1971

13. Garcia C.E and Morani M, " Design procedure for multivariable systems" American chemical society $472-484,1985$

14. Gupta Sanjay, John, 2005, "virtual instrumentating using labview, Tata McGraw Hill New Iselhi

15. Haggblom, 1993 "Experimental comparison of conventional and nonlinear mode Based control of a mixing Tank, American chemical society.

16. Hall R.C and Seborg, 1989 "Modelling and selfTuning control of a multivariable $\mathrm{PH}$ Neutralization process part I: modeling and multiloop control", American control conference, pp $1822-1828$,

17. Hang C.C, Improvement of transient response by means of variable set point weighting", IEEE transaction on industrial Electronics vol 43, pp 477-484, 1996

18. Henson M.A, Ogunnaike B.A and Schwaber, "Habitutating control strategies for process control AICHE journal, Vol 41, pp 604 - 616, 1995

19. Jota F.G, Braga A.R and Pena R.T "Performance assessment of advanced process control algorithms using an interacting tank system". Industry Application Conference Thirtieth I AS annual meeting IAS 95, Vol 2 PP $1565-1571,1995$

20. Ogunaike B, and Ray W.H, Process Dynamics Modeling and Control, oxford University, 1994.

21. Seborg D.E, Edgar T.F and mellichamp D.A, Process Dynamics and control, Wiley series in Chemical Engineering 1994

22. Wang W, Li.D and Xue Y. Decentralized Two Degree of freedom PID Tuning method for MIMO processes, proceedings of IEEE international symposium on industrial electronics (ISIE 2009) konea pp 143 - 1482009

23. Wayne B "process control modeling, Design and simulation prentice Hall (2003)

24. Ziegler J.G and Nicholas N.B, Optimum settings for Automatic Controllers " Trans ASME, vol 64, 1942 